\title{
DE QUAL FORMAÇÃO PROFISSIONAL ESTAMOS FALANDO? UMA QUESTÃO COLOCADA AOS INSTITUTOS FEDERAIS
}

\author{
Tarcísio Araujo Kuhn Ribeiro ${ }^{1}$ \\ 1 Instituto Federal de Educação, Ciência e Tecnologia de Brasília, Câmpus Planaltina \\ tarcisiokuhn@yahoo.com.br
}

Artigo submetido em 24/10/2012 e aceito em 08/11/2012.

\section{RESUMO}

$\mathrm{O}$ artigo visa fomentar o debate sobre a concepção de trabalho predominante em dois campi dos Institutos Federais de Brasília e de Goiás, sendo, respectivamente, o campus Planaltina e Uruaçu. Também foi analisada a legislação pertinente à educação profissional e aos Institutos Federais e ainda a literatura sobre o tema. Parte-se da contraposição de duas concepções de trabalho antagônicas, quais sejam: a visão do trabalho como valor de troca e a visão do trabalho como de uso. A primeira completamente alinhada com valores liberais capitalistas e a segunda aderente à teoria marxista socialista.
O trabalho de campo contou com aplicação de questionários com 0 grupo de professores das áreas técnicas, em que se abordou a percepção de cada docente sobre as duas visões de trabalho e ainda se procurou investigar o nível do debate teórico sobre 0 tema. Embora com uma abrangência pequena, apenas dois campi, a pesquisa de campo revelou dados interessantes sobre o problema em questão, os quais, quando confrontados com a legislação e a literatura pertinentes, possibilitam uma melhor compreensão do atual estágio desse debate.

PALAVRAS-CHAVE: Trabalho; Instituto Federal; Educação Profissional e Tecnológica.

\section{Wich professional training are we talking about? A question aimed at Federal Institutes of Brazil}

\section{ABSTRACT}

The article aims to promote the debate about the work conceptions that are predominate in two campuses of the Brazilian Federal Institute of Education, Science and Tecnology, of Brasília and Goias States, being respectively, Planaltina and Uruaçu. It was also analyzed the law about vocational education and Federal Institutes and still the literature on the subject. It starts with the contrast of two antagonistic
Fieldwork included questionnaires with the group of teachers in technical areas where they addressed the perception of each teacher on the two visions of work and still tried to investigate the level of theoretical debate on the subject. Although with a small scope, only two campuses, field research revealed interesting data on the problem at hand that when confronted with the law and relevant literature, provide a better understanding of the current stage of this 


\section{RIBEIRO (2012)}

conceptions of work, which are: a vision of debate.

work as exchange value and vision of

work as usage. The first fully aligned with

liberal capitalist values and the second adhering to Marxist values.

KEY-WORDS: Work; Brazilian Federal Institute; Vocational and technological education. 


\section{DE QUAL FORMAÇÃO PROFISSIONAL ESTAMOS FALANDO? UMA QUESTÃO COLOCADA AOS INSTITUTOS FEDERAIS.}

Este artigo visa fomentar o debate sobre a concepção predominante atribuída à categoria trabalho nos documentos legais relacionados à rede de Institutos Federais de Educação, Ciência e Tecnologia. Objetiva ainda, especificamente, analisar como esta concepção está disseminada em dois campi da rede federal. Para tanto, foram analisadas, inicialmente, a Lei n. -9.394 , de 20/12/1996 (Diretrizes e bases da educação nacional - LDB), e a Lei n. $\stackrel{0}{11.892}$, de 29/12/2008 (Institui a Rede Federal de Educação Profissional, Científica e Tecnológica e cria os Institutos Federais), e foram feitas pesquisas empíricas no Campus Planaltina, do Instituto Federal de Brasília, e no Campus Uruaçu, do Instituto Federal de Goiás, envolvendo quarenta e um professores, todos não licenciados e de áreas técnicas variadas".

O marco conceitual adotado nesta análise considera duas concepções antagônicas sobre a categoria trabalho, quais sejam: 1. Trabalho como valor de troca, como mercadoria que é vendida aos donos dos meios de produção em troca de salário. Trata-se da concepção hegemônica sob a era do capital. 2. Trabalho como valor de uso, "criador e mantenedor da vida humana em suas múltiplas e históricas necessidades e, como decorrência dessa compreensão, princípio educativo" (FRIGOTTO, 2002). Esta formulação é oriunda da teoria do pensador alemão Karl Marx e serve para iluminar não apenas duas posturas diferentes sobre o sentido do trabalho, mas também e, principalmente, para delimitar duas visões de mundo antagônicas.

$\mathrm{Na}$ primeira concepção, o trabalho é mais um dos meios necessários para a acumulação de capital, assim como também serve a este fim a propriedade, a ciência e a tecnologia. No capitalismo, todos esses fatores perdem a centralidade como valor de uso, ou seja, de responderem às necessidades vitais dos seres humanos. Por isso o foco de preocupação da maioria das pesquisas científicas atuais não é resolver problemas sociais, mas proporcionar lucro para os investidores e patrocinadores. Ainda que estas pesquisas possam contribuir de fato para a resolução de problemas sociais, sua preocupação principal não é essa; o foco é comercial. Por isso multiplicam-se as indagações do tipo: - Por que tantos engarrafamentos nas grandes cidades e por que cada carro leva apenas uma pessoa? Isso acontece porque o objetivo principal do desenvolvimento tecnológico automobilístico é vender carros e não resolver as necessidades de locomoção, muito embora também sirva a este fim. Se o objetivo principal fosse resolver problemas de locomoção, o investimento maciço seria em tecnologias de transporte coletivo e veículos de menor porte, por exemplo. Da mesma forma o foco principal do trabalho no capitalismo não é satisfazer as necessidades humanas, mas proporcionar lucro por meio da exploração da mão de obra. Ou como Marx definiu, da apropriação da mais-valia ${ }^{2}$.

1 As principais áreas técnicas envolvidas na pesquisa foram: Agronomia, Engenharia Civil, Engenharia de Alimentos, Engenharia Florestal, Engenharia Agrícola, Informática, Química, Medicina Veterinária e Zootecnia.

$2 \mathrm{Na}$ definição de Marx, mais-valia pode ser entendida como a apropriação pelo capitalista de parte do tempo trabalhado do operário. Para ilustrar, pode-se dizer que, descontado o valor (custo) do produto e a parte que o capitalista paga ao operário sob a forma de salário, o que sobre é a mais-valia.

EIXO, v. 1, n. 2 


\section{RIBEIRO (2012)}

Já a concepção de trabalho como valor de uso pode ser sintetizada nas palavras do próprio Marx:

O trabalho, como criador de valores de uso, como trabalho útil, é indispensável à existência do homem - quaisquer que sejam as formas de sociedade - é necessidade natural e eterna de efetivar o intercâmbio material entre o homem e a natureza, e, portanto, de manter a vida humana (MARX, 1982, apud FRIGOTTO, 2002, p. 13)

É este contexto de disputa - sobre qual concepção de trabalho deve prevalecer na educação profissional - que foi alvo das pesquisas empíricas preliminares desenvolvidas nos Campus Planaltina e Uruaçu dos Institutos Federais citados, cujos resultados serão apresentados ao longo deste artigo.

De toda crítica ao modo de produção capitalista, seja pela imposição da visão hegemônica do trabalho como mercadoria, seja por outras tantas questões críticas, como, por exemplo, de ordem ambiental, social ou econômica, uma pergunta inquietante ecoa do senso comum: - Qual a alternativa ao capitalismo? É certo que em um período da história dos séculos XIX e XX a resposta foi o socialismo. Contudo, a falência dos regimes socialistas e o chamado capitalismo de Estado praticado na China excluíram, por hora, a possibilidade dessa resposta. E então?

Sadi Dal Rosso demonstra estar preocupado e atento a esta questão, quando diz:

ou construímos uma utopia ou nos resignamos com a racionalidade intrínseca dos modos de acumulação de capital que gera desigualdades socioeconômicas. Desigualdade socioeconômica não é um princípio fundante para uma vida com sentido. [...] Prescindir de uma utopia do trabalho significa lançar os humanos na resignação da escravatura (DAL ROSSO, 2003, p. 8-9).

Ao considerar-se que o capitalismo não é capaz de resolver os problemas sociais e ambientais da atualidade e que devido a sua organização estrutural nunca terá esse objetivo, então fica clara a necessidade de se construírem alternativas que deem suporte ao surgimento de novas formas de organização socioeconômica capazes de responderem aos dilemas contemporâneos da humanidade. Entre essas, destaca-se a discussão sobre trabalho e sobre a formação para o trabalho.

Muitos estudos atuais reforçam a centralidade da categoria trabalho. E embora existam autores que defendam o fim do trabalho baseados em dados empíricos, estes utilizam como fontes, em sua maioria, pesquisas efetuadas na Europa; portanto derivam suas análises do contexto socioeconômico daquela região. Por outro lado outros pensadores têm reiterado a importância do debate para o entendimento da realidade atual. Entre os autores brasileiros que se destacam está Ricardo Antunes. Para ele, de fato

verificou-se uma desproletarização do trabalho industrial, fabril, nos países de capitalismo avançado. Em outras palavras, houve uma diminuição da classe operária industrial tradicional. Mas, paralelamente, efetivou-se uma significativa subproletarização do trabalho. (ANTUNES, 1998, p. 209) 


\section{RIBEIRO (2012)}

Além do mais a redução dos empregos industriais não se verificou em todas as partes do planeta e continua crescendo em algumas regiões. E mesmo que se aceite a redução dos empregos fabris como tendência, é preciso entender que a exploração do trabalho como mercadoria está na base estrutural do capitalismo, constitui parte da sua gênese e continuará existindo, mesmo que sob outras faces. Resumindo, o que houve foi uma "desproletarização do trabalho manual, industrial e fabril; heterogeneização, subproletarização e precarização do trabalho. Diminuição do operariado industrial tradicional e aumento da classe-que-vive-do-trabalho." (ANTUNES, 1998, p. 211).

$\mathrm{Na}$ esteira da afirmação e reafirmação da centralidade do trabalho, consolida-se no cenário brasileiro e mundial a importância crescente atribuída à educação profissional e tecnológica. Em 2008 o governo federal brasileiro instituiu a Rede Federal de Educação Profissional, Científica e Tecnológica e criou os Institutos Federais, por meio da Lei n.. 11.892/08, iniciando a expansão da rede federal de oferta pública e gratuita de formação profissional.

Nesse dispositivo legal consta, no caput do artigo $2^{\circ}$, a caracterização dos Institutos como entidade de ensino:

Os Institutos Federais são instituições de educação superior, básica e profissional, pluricurriculares e multicampi, especializados na oferta de educação profissional e tecnológica nas diferentes modalidades de ensino, com base na conjugação de conhecimentos técnicos e tecnológicos com as suas práticas pedagógicas. (BRASIL. Lei n.o $11.892 / 08)$

Por essa caracterização pode-se perceber a enorme abrangência da atuação atribuída aos Institutos Federais (IFs). A previsão legal de organização pedagógica "pluricurricular" demonstra a preocupação do legislador em incorporar uma ampla gama de formações profissionais e tecnológicas. Contudo a ausência do conceito de politecnia nesse dispositivo sugere que a amplitude desejada, expressa no termo "pluricurricular", não significa um direcionamento para a formação ampla e politécnica para o trabalho, mas, sim, indica o objetivo de ofertar um leque diversificado de cursos profissionalizantes.

A ideia de formação politécnica é fundamental para a sustentação da tese do trabalho como valor de uso. Segundo Dermeval Saviani

Politecnia diz respeito ao domínio dos fundamentos científicos das diferentes técnicas que caracterizam o processo de trabalho produtivo moderno. Está relacionada aos fundamentos das diferentes modalidades de trabalho e tem como base determinados princípios, determinados fundamentos, que devem ser garantidos pela formação politécnica. Por quê? Supõe-se que, dominando esses fundamentos, esses princípios, o trabalhador está em condições de desenvolver as diferentes modalidades de trabalho, com a compreensão do seu caráter, sua essência. Não se trata de um trabalhador adestrado para executar com perfeição determinada tarefa e que se encaixe no mercado de trabalho para desenvolver aquele tipo de habilidade. Diferentemente, trata-se de propiciar-Ihe um desenvolvimento multilateral, um desenvolvimento que abarca todos os ângulos da prática produtiva, na medida em que ele domina aqueles princípios que estão na base da organização da produção 


\section{RIBEIRO (2012)}

moderna. (SAVIANI, 2003, apud MOURA, 2010, p. 880)

Ou seja, formar para o trabalho, para o domínio dos fundamentos tecnológicos, para a compreensão das relações constituintes do mundo do trabalho e suas consequências para a realidade coletiva e individual. Tudo isso é muito diferente de treinamento técnico para executar tarefas específicas.

Uma conclusão parcial é que a análise da Lei $n .{ }^{\circ} 11.892 / 08$ isolada não é suficiente para definir a visão de trabalho predominante, possibilitando apenas formular hipótese e colher indícios, já que neste particular a legislação não dá maiores pistas. Para consolidar um entendimento, é necessário ampliar esse estudo para outras legislações e, sobretudo, para documentos institucionais do Ministério da Educação (MEC).

Por outro lado, a Lei 9.394/96, de cunho mais geral e que estabelece as diretrizes e bases da educação nacional, apresenta concepções que se aproximam mais da visão de trabalho como valor de uso. No seu artigo 1일: "A educação abrange os processos formativos que se desenvolvem na vida familiar, na convivência humana, no trabalho, nas instituições de ensino e pesquisa, nos movimentos sociais e organizações da sociedade civil e nas manifestações culturais." (BRASIL. Lei 9.394/96). Ainda neste artigo, o seu parágrafo segundo diz: "A educação escolar deverá vincular-se ao mundo do trabalho e à prática social."

O capítulo III da Lei é dedicado especificamente à Educação Profissional, percebendo-se uma atenção concentrada na capacitação e menos na formação integral do cidadão. O artigo 39 estabelece que "a educação profissional, integrada às diferentes formas de educação, ao trabalho, à ciência e à tecnologia, conduz ao permanente desenvolvimento de aptidões para a vida produtiva." (Grifo nosso)

A análise das duas Leis permite concluir que o debate aqui proposto sobre as concepções de trabalho não esteve em pauta ou não foi incorporado nessas legislações. Mas ao trazer ideias como a de "desenvolvimento de aptidões para a vida produtiva" (Art. 39 da Lei 9.394/96), por exemplo, embora não esteja especificado o que seria "vida produtiva", se for considerada a força da ideologia hegemônica nesse contexto, pode ser levantada a hipótese de que existe uma aproximação conceitual com a visão de trabalho como valor de troca.

De acordo com a literatura consultada (ANTUNES, 1998; CARVALHO, 2003; FRIGOTTO, 2002), percebe-se que o trabalho e a educação para o trabalho ocupam lugar de destaque no processo de reprodução da vida humana e que assim será por muito tempo. Contudo, não resta dúvida que o desenvolvimento das tecnologias produtivas, com a incorporação crescente da microeletrônica, modificou as relações de trabalho e as relações entre trabalho e educação. A demanda por mão de obra nas atividades industriais foi reduzida substancialmente, o que impulsionou a formação de um exército de desempregados, pressionando os trabalhadores a aceitarem redução de salários e a flexibilização de direitos trabalhistas. Por outro lado, a introdução da microeletrônica exige que os trabalhadores possuam uma formação profissional mais qualificada que aquela exigida anteriormente, o que abre espaço para o crescimento das ações de educação profissional ou, como coloca Olgamir Carvalho (2003, p. 15), "na perspectiva da educação do trabalho".

Ainda segundo Carvalho (2003, p. 16)

a natureza das mudanças técnicas ocorridas, especialmente, com o advento da microeletrônica, torna possível o pressuposto de que as novas 


\section{RIBEIRO (2012)}

opções tecnológicas e organizacionais (novo paradigma técnicoeconômico), portam possibilidades de valorização da qualificação dos trabalhadores e a educação profissional pode jogar um papel decisivo nesse processo [...] que possibilita integrar a educação como processo de desenvolvimento pessoal, com a educação requerida pelo novo paradigma.

O que se levanta é o potencial transformador da educação profissional, uma vez que a própria manutenção do capitalismo, na sua configuração atual, depende dessa formação educacional. É nessa linha que Carvalho aponta a necessidade de compreender as demandas "para a educação profissional no capitalismo contemporâneo e as respostas que ela pode dar, tanto no sentido de uma educação do capital e, portanto, para consolidar a sua hegemonia, ou uma educação do trabalho, e, por conseguinte, instrumento de contra-hegemonia." (CARVALHO, 2003, 17-18).

Trata-se de uma perspectiva inovadora para a educação profissional e tecnológica, perspectiva esta que se articula com a visão de trabalho como valor de uso, observandose que este tipo de trabalho coaduna-se com uma visão contra-hegemônica. Portanto, analisar a concepção de trabalho predominante na legislação que trata da educação profissional e a visão dos profissionais que fazem esta educação é essencial para construir um diagnóstico do caminho que estão seguindo os Institutos Federais: se o da "educação do capital", se o da "educação do trabalho", ou ainda se predomina uma posição ambígua.

Nesse sentido, serão apresentados resultados das pesquisas de campo realizadas para compor este artigo, que subsidiaram uma caracterização das concepções de trabalho presentes nos discursos dos professores de áreas técnicas dos campi Planaltina e Uruaçu. Para tanto, foram aplicados 41 questionários com professores das áreas técnicas, a maioria de não licenciados. Apenas dois obtiveram a licenciatura via programas de formação no trabalho.

O recorte espacial da pesquisa - Campi Planaltina e Uruaçu - foi definido pela viabilidade de acesso aos professores. O recorte por área de atuação e formação acadêmica - área técnica e não licenciados - deveu-se à preocupação em examinar especificamente os responsáveis pelo ensino da técnica em si, uma vez que uma mudança de paradigma no ensino profissional passa, necessariamente, por uma mudança de postura daqueles que transmitem a técnica de produção e não apenas pelos responsáveis pela educação científica de base, de cunho mais filosófico, que são os professores da área propedêutica.

A primeira pergunta versava sobre o conceito de empregabilidade. Foi apresentado um pequeno texto conceituando o termo e depois foram colocadas opções que variavam entre a concordância e a discordância com a ideia de empregabilidade no contexto geral do mundo do trabalho contemporâneo. Do total de 41 professores entrevistados, 22 responderam que concordavam, sendo 16, do Campus Planaltina, e 06, do Campus Uruaçu. Isso representa 53,6\% do total.

Entende-se que a ideia de empregabilidade transfere ao trabalhador a responsabilidade por obter e manter seu emprego. Isso parece lógico, não fosse a existência de uma situação de desemprego estrutural no capitalismo. Considera-se aqui que a ideia de empregabilidade está associada à visão do trabalho como valor de troca. Então, tem-se que mais da metade dos professores entrevistados neste quesito deixam transparecer sua postura ideológica condizente com o trabalho como valor de troca.

Em uma outra pergunta foi questionado se os termos trabalho, profissão e 


\section{RIBEIRO (2012)}

emprego significam a mesma coisa. No Campus Planaltina todos os 30 respondentes disseram que não, enquanto em Uruaçu, 09 disseram que sim. Esta questão foi proposta com o objetivo de averiguar a existência de alguma reflexão sobre a categoria trabalho, no grupo de professores. Considerou-se que aqueles que não veem diferença entre os termos possuem pouca ou nenhuma reflexão teórica sobre o trabalho como categoria de estudo, haja vista que os termos indicam ideias diferentes. Ao não refletirem sobre os problemas teóricos relacionados ao trabalho, os professores tendem a reproduzir a ideologia dominante sem reservas, qual seja a visão do trabalho como valor de troca. Esta postura configura-se em um impasse importante para aqueles que defendem a utilização da educação profissional também como alavanca para ideias e posturas contra-hegemônicas.

É interessante destacar que quando foi feita uma solicitação direta aos professores para escolherem entre as concepções de trabalho como valor de uso e valor de troca, a maioria optou pelo trabalho como valor de uso. Este questionamento foi feito da seguinte forma:

Analisando as relações entre trabalho e educação profissional colocadas abaixo e de acordo com sua experiência vivida, qual opção satisfaz melhor o seu entendimento para o tema?

(A) Trabalho é uma atividade criadora e mantenedora da vida humana em suas necessidades; por isso a educação profissional deve preparar 0 futuro trabalhador para o exercício da cidadania plena.

(B) Trabalho é uma atividade fundamental que possibilita a aquisição de bens diversos necessários à sobrevivência de cada ser humano; por isso a educação profissional deve preparar o futuro trabalhador para exercer bem uma profissão.

A opção de 30 professores (73,17\%) foi pela letra $A$. As respostas a este item demonstram uma contradição com 0 resultado das respostas do item sobre empregabilidade, quando 53,6\% concordaram com a ideia de empregabilidade.

Outra questão levantada foi sobre o papel da educação profissional. Foi solicitado aos professores que respondessem, considerando uma escala de um a dez, em que 01 equivale a discordo totalmente, e dez equivale a concordo totalmente, qual pontuação ele atribuiria à seguinte afirmativa: "A educação profissional deve cumprir satisfatoriamente dois papéis fundamentais: formar os futuros profissionais para o mercado de trabalho e formar futuros profissionais para o exercício da cidadania plena". À medida que as pontuações se aproximassem de 10, teríamos uma tendência de concordância com a visão de trabalho como valor de uso. O gráfico a seguir apresenta os resultados consolidados dos dois Campi. 


\section{RIBEIRO (2012)}

\section{Gráfico 1}

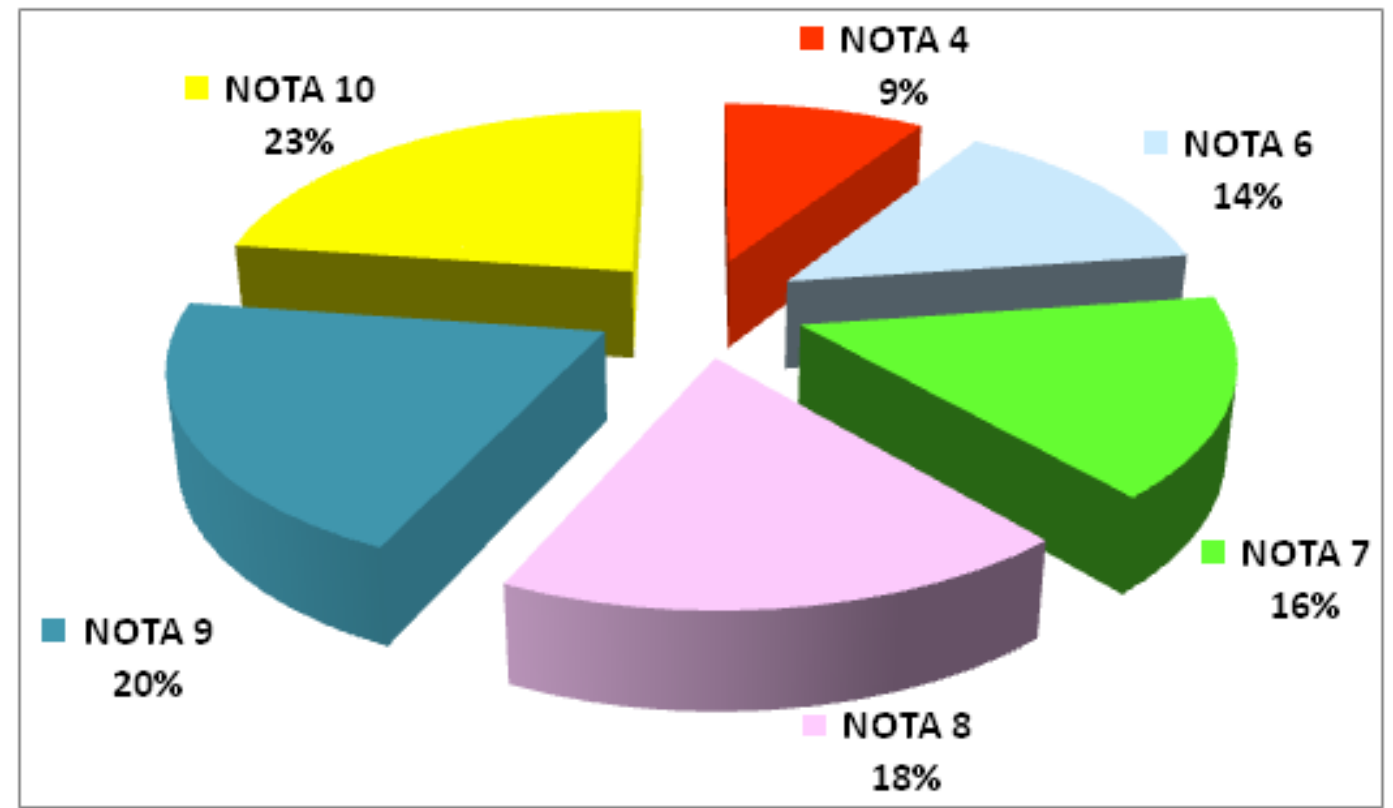

Fonte: do autor. Pesquisa de campo.

Mais uma vez se percebe a predominância da visão do trabalho como valor de uso. Na mesma linha de interpretação colocada anteriormente, sempre que interrogados diretamente, os professores optam pela concepção de trabalho mais próxima da visão de uso. Quando a indagação foi feita indiretamente, por meio do conceito de empregabilidade, pouco mais da metade optou pela visão do trabalho como valor de troca, e os demais, representando $46,4 \%$, optaram pelo valor de uso.

O que se pode concluir, de forma preliminar, é que no ambiente desses Campi existe espaço para o diálogo com os professores da área técnica sobre a concepção de trabalho que deve predominar na educação profissional e tecnológica nos campi. Embora a viabilização na prática da implantação da concepção do trabalho como valor de uso nos currículos seja um caminho árido, os resultados colhidos até aqui apontam favoravelmente no sentido defendido por Carvalho (2003) e outros, de

assumir a centralidade que a educação tem tido no debate atual e, a partir das novas condições que se apresentam, incorporá-la como elemento central não apenas do debate dos educadores e dos especialistas dos diferentes setores, mas torná-la pauta efetiva de luta de todos os trabalhadores, que concebem a educação como prática social transformadora. (CARVALHO, 2003, p. 19-20)

A questão está colocada aos Institutos Federais e aos seus professores. Qual a formação profissional que queremos praticar? Se, além da qualificação profissional, também haverá espaço para o desenvolvimento de uma educação progressista, no sentido freiriano, voltada para o exercício da cidadania plena e para a construção de práticas sociais transformadoras. 


\section{RIBEIRO (2012)}

\section{REFERÊNCIAS}

ANTUNES, Ricardo. Os sentidos do trabalho: ensaios sobre a afirmação e a negação do trabalho. 5. ed. São Paulo: Boitempo Editorial, 1999.

BRASIL. Lei n.․ 9.394, de 20 de dezembro de 1996. Estabelece as diretrizes e bases da educação nacional. Diário Oficial [da] República Federativa do Brasil, Brasília, DF, 23 dez. 1996. Seção 1, p. 27833.

BRASIL. Lei n.. 11.892, de 29 de dezembro de 2008. Institui a Rede Federal de Educação Profissional, Científica e Tecnológica, cria os Institutos Federal de Educação, Ciência e Tecnologia, e dá outras providências. Diário Oficial [da] República Federativa do Brasil, Brasília, DF, 30 dez. 2008. Seção 1, p. 1.

CARVALHO, Olgamir Francisco de. Educação e formação profissional: trabalho e tempo livre. Brasília: Plano Editora, 2003.

DAL ROSSO, S. Prefácio. In: CARVALHO, Olgamir Francisco de. Educação e formação profissional: trabalho e tempo livre. Brasília: Plano Editora, 2003.

FREIRE, Paulo. Pedagogia da autonomia: saberes necessários à prática educativa. São Paulo: Paz e Terra, 1996. (Coleção Leitura)

FRIGOTTO, Gaudêncio. A dupla face do trabalho: criação e destruição da vida. In: ; CIAVATTA, Maria (Orgs.). A experiência do trabalho e a educação básica.

Rio de Janeiro: DP\&A, 2002. p. 11-27.

MOURA, Dante Henrique. A Relação entre a educação profissional e a educação básica na CONAE 2010: possibilidades e limites para a construção do novo Plano Nacional de Educação. Educação e Sociedade. Campinas, vol.31, n.112, p. 875-894, set. 2010. 